\title{
Role of vitamin D supplementation in asthma and seasonal allergic rhinitis in eastern India
}

\author{
Manuprita Sharma ${ }^{1}$, Anindita Banerjee ${ }^{2}$, Vineet Kumar Khemka ${ }^{3}$, Ravela Malathi ${ }^{4}$, \\ Sukanta Sen ${ }^{5}$, Bidhan Ray ${ }^{6}$, Santosh Raman \\ ${ }^{1}$ Assistant Professor, ${ }^{6}$ Associate Professor, Department of ENT, ${ }^{2,3}$ Assistant Professor, ${ }^{4}$ Associate Professor, \\ Department of Biochemistry, ${ }^{5}$ Associate Professor, Department of Pharmacology, ICARE Institute of Medical Sciences \\ and Research, Haldia, West Bengal, ${ }^{7}$ Associate Professor, Department of ENT, Mata Gujri Memorial Medical College, \\ Kishanganj, Bihar, India
}

Background: Allergic rhinitis (AR) known to be a common type of chronic rhinitis which affects $10-20 \%$ of the general population while asthma is another major health problem and leading cause of morbidity in the worldwide. Vitamin D, a steroid hormone known for its important role in immunological effects has a role in AR and asthma. Aims and Objectives: The aim of our study was to assess the serum vitamin $D$ levels in patients with asthma and seasonal AR pre-treatment or post treatment with oral vitamin D supplementation (cholecalciferol $1000 \mathrm{IU})$ and to study the pathogenesis of the disease. Materials and Methods: The study included 66 AR and asthma patients and 46 control subjects. Fasting serum samples of control and AR subjects were analyzed for routine biochemical parameters immediately after collection while aliquots of the samples were also stored at $-20^{\circ} \mathrm{C}$ for the assay of 25 -hydroxyvitamin $D$ by ELISA. Results: Serum vitamin D levels were found to be significantly lower in AR and asthma patients compared with controls $(p<0.0001)$. On receiving vitamin $D$ supplementation (cholecalciferol - $1000 \mathrm{IU}$ ) we found an increase in vitamin D serum levels in AR and asthma patients as compared to controls $(p<0.0001)$. Conclusion: Supplementation of vitamin D may be beneficial in the prevention of the pathogenesis of AR and asthma.

Key words: Vitamin D, Asthma, Allergic rhinitis, Cholecalciferol
Access this article online

\section{Website:}

http://nepjol.info/index.php/AJMS

DOI: 10.3126/ajms.v8i3.16508

E-ISSN: 2091-0576

P-ISSN: 2467-9100

\section{INTRODUCTION}

Allergic rhinitis (AR) known to be a common type of chronic rhinitis which affects $10-20 \%$ of the general population, has been associated with significant impairments in quality of life, sleep, and work performance. ${ }^{1}$ On the other hand, Asthma is another major health problem and leading cause of morbidity in the worldwide whose prevalence increased from nearly three decades in western and industrialised countries although the causes of the "asthma epidemic" are incompletely understood. ${ }^{2,3}$

Vitamin D, a steroid hormone known for its important role in regulation of calcium metabolism and mineralisation of bone also has number of immunological effects. In recent years, the world-wide increase in asthma and chronic rhinitis has been associated with low vitamin $\mathrm{D} .{ }^{4}$ The association between low serum vitamin $\mathrm{D}$ levels and an increase in immune disorders may be due to sedentary lifestyle, leading to less sun exposure and less cutaneous vitamin D production. ${ }^{5,6}$ The growing data also points out that vitamin D plays an important role in the protection against allergic diseases like rhinitis and asthma.

The role of vitamin $\mathrm{D}$ in asthma and seasonal allergic rhinitisis still controversial and several studies designed till date has shown different results. In India, vitamin D insufficiency/deficiency has been emerging in recent years. The treatment of vitamin D deficiency may be rectified and it could prevent asthma and seasonal AR upto some extent. None of the study has shown the effect of vitamin $\mathrm{d}$ supplementation in AR as well as in asthma in eastern India. Thus the aim of our study was to assess the serum vitamin $\mathrm{D}$ levels in patients with asthma and seasonal 
AR pre-treatment or post treatment with oral vitamin $\mathrm{D}$ supplementation (cholecalciferol - $1000 \mathrm{IU}$ ) and to study the pathogenesis of the disease.

\section{MATERIALS AND METHODS}

The study included $66 \mathrm{AR}$ and/or asthma patients and 46 control subjects. The patients for this study were selected from the 'ENT Outpatient Department' of ICARE Institute of Medical Sciences \& Research, Haldia, a tertiary care hospital in the eastern part of India. The healthy control subjects were age and sex matched. Informed consent was obtained from every control subject as well as from AR and/or asthma patients. The inclusion criteria having a history of AR and/or asthma with eosinophilia on blood or nasal smear present. The AR patients received fluticasone nasalspray for a short duration to relieve acute phase without vitamin D3 which was followed supplementation of oral vitamin $\mathrm{D}_{3}$ (cholecalciferol; $1000 \mathrm{IU}$ ) in case of deficiency for more than 15 days. The study was cleared by the Institutional Human Ethics Committee according to Helsinki guidelines. All the healthy control subjects were also examined clinically to exclude any AR and/or asthmatic symptoms. The exclusion criteria in AR and/or asthma group included diabetes mellitus, overt cardiovascular disease, rheumatoid arthritis, cystic fibrosis, ulcerative colitis, rickets, osteomalacia, thyroid dysfunctions, chronic kidney disease, cancer, chronic infection, and any other associated neurological disease.

\section{Biochemical Assays}

Fasting serum samples of control and AR subjects were analyzed for routine biochemical parameters immediately after collection while aliquots of the samples were also stored at $-20^{\circ} \mathrm{C}$ for the assay of 25-hydroxyvitamin D.

\section{Immunoassays}

Serum vitamin $\mathrm{D}$ was measured as 25 -hydroxyvitamin $\mathrm{D}$ is considered as the indicator of vitamin D. 25-hydroxyvitamin D was measured by using commercially available ELISA kits (Calbiotech, USA). Anti-25-hydroxyvitamin D antibody (capture antibody) coated wells were incubated with standards (25-hydroxyvitamin D), samples and vitamin D-biotin conjugate at room temperature for 90 minutes. The binding of vitamin D-biotin conjugate to the wells by the capture antibody decreased by competition with 25-hydroxyvitamin D present in the standards or samples. Following a wash step, bound vitamin D-biotin was detected with streptavidin-horse radish peroxidase (SA-HRP) using tetramethylbenzidine (TMB) as the substrate. For drawing the calibration curve from the measured absorbance readings, a 4- parametric logistic (4-PL) curve was used.

\section{Statistical Analysis}

For two normally distributed sample groups, the means were compared by Student's unpaired't' test. A value of $p<0.05$ was considered as statistically significant. The statistical analysis was performed by using Graph Pad prism software (version 5, 2007, Sandiego, California, USA).

\section{RESULTS}

The demographic profile of the patients and control is depicted in Table 1. The age, sex and BMI were adjusted in both the groups (Table 1). The mean \pm SD of vitamin $\mathrm{D}$ was $31.87 \pm 5.18$ in control subjects while $15.75 \pm 6.04 \mathrm{ng} / \mathrm{ml}$ in AR and/or asthma patients which shows statistically significant $(p<0.0001)$ (Figure 1$)$.

On receiving vitamin $\mathrm{D}$ supplementation (cholecalciferol - $1000 \mathrm{IU}$ ) there was a significant rise in serum vitamin $\mathrm{D}$ levels in $\mathrm{AR}$ and/or asthma patients $(20.36 \pm 4.35)$ compared with controls $(\mathrm{p}<0.0001)$ (Figure 2).

\section{DISCUSSION}

The role of vitamin D apart from bone and calcium metabolism has increased significantly and recent studies have suggested its plausible role as an immuno-modulator in allergic rhinitis as well as in asthma. It plays an important role in the regulation of immune system, lymphocyte function, $T$ cell antigen receptor signalling or activation, cytokine production. ${ }^{7,8,9}$ Vitamin $\mathrm{D}_{3}$ is synthesized in the human body by a photochemical reaction (ultraviolet B 297-315nm) from 7-dehydrocholesterol and is also consumed in the diet. Vitamin $\mathrm{D}$, in either $\mathrm{D}_{2}$ or $\mathrm{D}_{3}$ form, is considered biologically inert until it undergoes two enzymatic hydroxylation reactions. At first, vitamin D binds

\begin{tabular}{|c|c|c|c|}
\hline \multirow[t]{2}{*}{ Parameters } & \multicolumn{2}{|c|}{ Mean $\pm S D$} & \multirow[t]{2}{*}{$p$ value } \\
\hline & Control $(\mathrm{N}=46)$ & $\begin{array}{c}\text { AR and/or } \\
\text { Asthma }(\mathrm{N}=66)\end{array}$ & \\
\hline Age & $31.26 \pm 4.78$ & $29.68 \pm 7.82$ & 0.2252 \\
\hline $\operatorname{Sex}(M / F)$ & $26 / 20$ [1.3:1] & $38 / 28$ [1.3:1] & \\
\hline $\mathrm{BMI}$ & $25.78 \pm 2.31$ & $24.92 \pm 1.78$ & 0.0282 \\
\hline $\begin{array}{l}\text { Fasting blood } \\
\text { glucose } \\
\text { (mg/dl) }\end{array}$ & $84.06 \pm 12.26$ & $88.24 \pm 9.46$ & 0.0443 \\
\hline $\begin{array}{l}\text { Serum total } \\
\text { cholesterol } \\
(\mathrm{mg} / \mathrm{dl})\end{array}$ & $182.31 \pm 23.12$ & $196.24 \pm 18.82$ & 0.0007 \\
\hline $\begin{array}{l}\text { Serum } \\
\text { triglycerides } \\
\text { (mg/dl) }\end{array}$ & $115.67 \pm 25.62$ & $122.24 \pm 17.82$ & 0.1121 \\
\hline
\end{tabular}




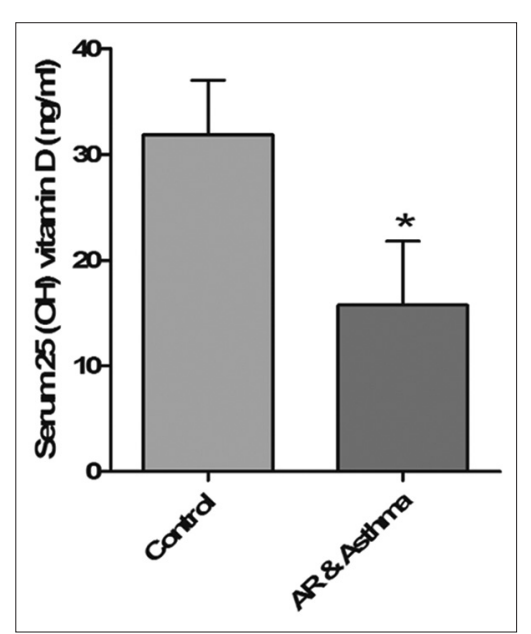

Figure 1: Vitamin D levels in AR and/or asthma patients and control subjects

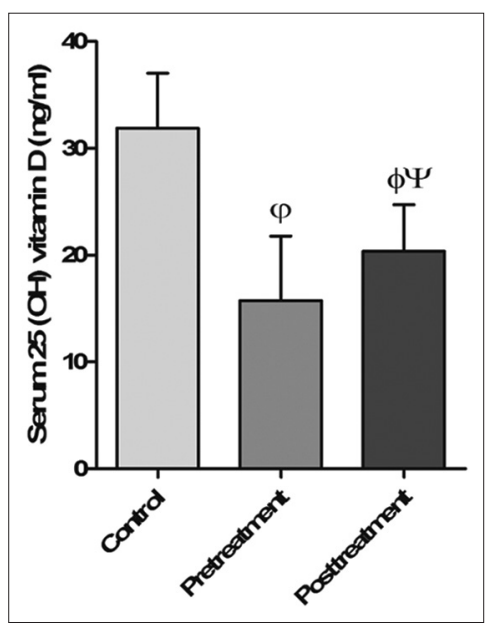

Figure 2: Vitamin D levels in AR and/or asthma patients and control subjects before and after treatment with vitamin $\mathrm{D}$ supplementation

carrier proteins in the skin (particularly the vitamin D binding protein or DBPs) and is transported to the liver where it is enzymatically hydroxylated by vitamin D-25-hydroxylase (CYP2R) on C-25 thereby generating $25(\mathrm{OH}) \mathrm{D}$ or calcidiol while second hydroxylation reaction in the kidney by 25(OH) D-1-OHase (CYP27B1) hydroxylates 25(OH) $\mathrm{D}$ at $\mathrm{C}-1 \alpha$ position and converts it to the biologically active form 1,25-dihydroxy vitamin $\mathrm{D}\left(1,25(\mathrm{OH})_{2} \mathrm{D}\right)$ or calcitriol. ${ }^{10}$ The $1,25(\mathrm{OH})_{2} \mathrm{D}$ concentration in the blood is regulated by a feedback mechanism and by the induction of parathyroid hormone, $\mathrm{Ca}^{2+}$, and various cytokines. ${ }^{11}$

Some studies link vitamin $\mathrm{D}$ with allergic rhinitis and asthma. An Australian study after observing that the prevalence of allergies increases in percentage, with the decrease of latitude, have shown that the inverse association between latitude and asthma is not dependent on ultraviolet but attributable to other climatic factors such as temperature. ${ }^{12} \mathrm{~A}$ study in Norway also showed a direct association between vitamin $\mathrm{D}$ deficiency and male sex for the development of allergic rhinitis, whereas females resulted protected according to VD levels. ${ }^{13}$ In our study we also found a significant decrease in vitamin D levels in allergic rhinitis patients which supports other studies (Figure 1).

Asthma is characterized by an increased activity of TH2 cells which results in the production of $\operatorname{IgE}$ and inflammatory cytokines and thus causes airway hyper-responsiveness and eosinophilic inflammation. Some studies have pointed out the protective role of vitamin D against asthma. ${ }^{14}$ One of the Spanish study it has been shown that higher maternal vitamin $\mathrm{D}$ at 12 weeks' gestation was not associated with wheezing at 1 year or 4 years or asthma at age 4 to 6 years. ${ }^{15}$ Another study from UK has not shown any association with dietary vitamin $\mathrm{D}$ and wheeze, asthma, or sensitization. ${ }^{16}$ A recent study showed an inverse relationship between serum concentration of vitamin Dand severity of asthma attacks and consumption of inhaled corticosteroids (ICS) while another observed that children with asthma had insufficient serum levels of vitamin D and observed an inverse correlation between VD, total $\operatorname{IgE}$ and skin prick tests (SPT) positivity, and a direct association with increased corticosteroid usage. ${ }^{17}$ Our study also shows that serum vitamin $\mathrm{D}$ levels are lower in $\mathrm{AR}$ and asthma while after vitamin D supplementation the levels tends to rise which supports other study (Figure 2). It may be plausible that vitamin $\mathrm{D}$ could modulate various cytokines induced effects through different cells of the immune system with a dosedependent action. The calculative doses of vitamin D might inhibit the production of both TH1 and TH2 cytokines., 18

Low blood levels of vitamin D have been linked to increased risk of asthma attacks in children and adults with asthma. There has been a growing interest in the potential role of vitamin $\mathrm{D}$ in asthma management, because it might help to reduce upper respiratory infections (such as the common cold) that can lead to exacerbations of asthma. Several clinical trials have tested whether taking vitamin $\mathrm{D}$ as a supplement has an effect on asthma attacks, symptoms, and lung function in children and adults with asthma. ${ }^{19}$

The researchers found that giving an oral vitamin D supplement reduced the risk of severe asthma attacks requiring hospital admission or emergency department attendance from $6 \%$ to around 3\%. They also found that vitamin $\mathrm{D}$ supplementation reduced the rate of asthma attacks needing treatment with steroid tablets. These results are based largely on trials in adults. ${ }^{19}$

From our study we have significantly found a decrease in levels of vitamin $\mathrm{D}$ in patients suffering from $\mathrm{AR}$ and 
asthma but nevertheless few limitations were there in our study which needs to be mentioned. All of the patients included in this study were adults and no paediatric children were involved. Secondly, few of the patients were taking some other drugs such as antihistamines, topical corticosteroids which might interfere with serum vitamin D levels. Another limitation of this study was less sample size. Despite these limitations it has been observed that serum vitamin $D$ levels were lower in patients suffering from $A R$ and asthma which increases gradually after supplementation of cholecalciferol. However, supplementation of vitamin $\mathrm{D}$ may be beneficial in the prevention of the pathogenesis of AR and asthma. Moreover, a large longitudinal study needs to be done to conclude the fact.

\section{CONCLUSION}

From our study we have significantly found a decrease in levels of vitamin $\mathrm{D}$ in patients suffering from AR and asthma. Supplementation of vitamin D may be beneficial in the prevention of the pathogenesis of AR and asthma.

Vitamin D has been found to offer some protection against severe asthma attacks in adults with mild to moderate asthma. Further trials focusing on children and people who experience frequent severe asthma attacks are needed before definitive clinical recommendations can be made.

\section{REFERENCES}

1. Dykewicz MS and Hamilos DL. Rhinitis and sinusitis. J Allergy Clin Immunol 2010; 125:S103-S115.

2. Masoli M, Fabian D, Holt $S$ and Beasley R. Global Initiative for Asthma (GINA) Program. The global burden of asthma: Executive summary of the GINA Dissemination Committee report. Allergy 2004; 59:469-478.

3. Litonjua $A A$ and Weiss ST. Is vitamin D deficiency to blame for the asthma epidemic? J Allergy Clin Immunol 2007; 120:1031-1035.

4. Schauber J and Gallo RL. Vitamin D deficiency and asthma: not a strong link--yet. J Allergy Clin Immunol 2008; 121:782-783.

5. Bener A, Ehlayel MS, Bener $\mathrm{HZ}$ and Hamid Q. The impact of Vitamin $D$ deficiency on asthma, allergic rhinitis and wheezing in children: An emerging public health problem. J Fam Community Med 2014; 21:154-161.

6. Modh D, Katarkar A, Thakkar B, Jain A, Shah P and Joshi K. Role of vitamin $D$ supplementation in allergic rhinitis. Indian $\mathrm{J}$ Allergy Asthma Immunol 2014; 28:35-39.

7. Baeke F, Takiishi T, Korf H, Gysemans $C$ and Mathieu C. Vitamin D: Modulator of the immune system. Curr Opin Pharmacol 2010; 10:482-496.

8. Akbar NA and Zacharek MA. Vitamin D: immunomodulation of asthma, allergic rhinitis, and chronic rhinosinusitis. Curr Opin Otolaryngol Head Neck Surg 2011; 19:224-228.

9. Hewison $M$. Vitamin $D$ and innate and adaptive immunity. Vitam Horm 2011; 86:23-62.

10. Prosser DE and Jones G. Enzymes involved in the activation and inactivation of vitamin D. Trends Biochem Sci 2004; 29:664-673.

11. Banerjee A, Khemka VK, Ganguly A, Roy D, Ganguly U and Chakrabarti S. Vitamin D and Alzheimer's disease: neurocognition to therapeutics. Int $\mathrm{J}$ Alzheimers Dis 2015; 2015:192747.

12. Hughes AM, Lucas RM, Ponsonby AL, Chapman C, Coulthard A, Dear $\mathrm{K}$, et al. The role of latitude, ultraviolet radiation exposure and vitamin D in childhood asthma and hay fever: An Australian multicenter Study. Pediatr Allergy Immunol 2011; 22:327-333.

13. Mai XM, Chen $Y$, Camargo $C A$ and Langhammer A. Serum 25-hydroxyvitamin $D$ levels and self-reported allergic rhinitis in Norwegian adults - The HUNT Study. Allergy 2014; 69:488-493.

14. Hollarns EM. Vitamin D, and atopy and asthma phenotypes in children. Curr Opin Allergy Clin Immunol 2012; 12:228-234.

15. Morales E, Romieu I, Guerra S, Ballester F, Rebagliato M, Vioque $\mathrm{J}$, et al. INMA Project. Maternal vitamin D status in pregnancy and risk of lower respiratory tract infections, wheezing, and asthma in offspring. Epidemiology 2012; 23:64-71.

16. Pike KC, Inskip HM, Robinson S, Lucas JS, Cooper C, Harvey NC, et al. Southampton Women's Survey Study Group. Maternal late-pregnancy serum 25-hydroxyvitamin D in relation to childhood wheeze and atopic outcomes. Thorax 2012; 67:950-956.

17. Searing DA, Zhang Y, Murphy JR, Hauk PJ, Goleva E and Leung DY. Decreased Serum Vitamin D levels in children with asthma are associated with increased corticosteroid usage. J Allergy Clin Immunol 2010; 125:995-1000.

18. Jirapongsananuruk $\mathrm{O}$, Melamed I and Leung DY. Additive immunosuppressive effects of 1,25-dihydroxyvitamin D3 and corticosteroids on $\mathrm{TH} 1$, but not $\mathrm{TH} 2$, responses. J Allergy Clin Immunol 2000; 106:981-985.

19. Martineau AR, Cates CJ, Urashima $M$, Jensen $M$, Griffiths AP, Nurmatov U, et al. Vitamin D for the management of asthma.Cochrane Database Syst Rev 2016; 9:CD011511.

\footnotetext{
Authors Contribution:

MS, AB and BR-Concept, design, data collection, manuscript editing and review; VKK, SS, RM and SR-Data analysis, literature search, manuscript preparation, editing and review.

Orcid ID:

Dr. Manuprita Sharma: http://orcid.org/0000-0001-6673-2253

Dr. Anindita: http://orcid.org/0000-0002-6328-8190

Dr Vineet Kumar Khemka: http://orcid.org/0000-0003-4375-5780

Dr Sukanta: http://orcid.org/0000-0002-8348-0251

Dr Santosh Raman: (i) http://orcid.org/0000-0001-7161-2037

Dr Bidhan Ray: (1) http://orcid.org/0000-0002-7936-3829

Source of Support: We acknowledge the Secretary, ICARE Institute of Medical Sciences and Research, Haldia, West Bengal for their kind support, Conflict of Interest: None declared.
} 